\title{
CONTAGEM DE CÉLULAS SOMÁTICASE ANÁLISES FÍSICO-QUÍMICAS \\ E MICROBIOLÓGICAS DO LEITE CRU TIPO C PRODUZIDO NA REGIÃO AGRESTE DO ESTADO DE PERNAMBUCO
}

\section{M. da C.G . de Lima', M J. de Sena' ${ }^{1}$, R.A. M ota ${ }^{1}$, E.S. Mendes ${ }^{1}$, C.C. de Almeida², R.P.P.E Silva ${ }^{2}$}

IUniversidade Federal Rural de Pernambuco, Departamento de Medicina Veterinária, R. Dom Manoel de Medeiros, s/ №, CEP 52171-900, Recife, PE, Brasil.

\section{RESUMO}

Objetivou-secomesteestudo avaliar ainfluência da contagem decélulas somáticas(CCS) sobre aqualidadedoleiteproduzido em 13 propriedades ruraisdoEstado dePernambuco. Estetrabal ho foi real izado tendo em vistaainstrução normativanำ51, publicada pelo Ministério daAgricultura, Pecuária eA bastecimento (MAPA), por intermédio do Departamento del nspeção deProdutos de Origem A nimal (DIPOA). Foram coletadas 301 amostras de leite cru tipo "C" de animais em lactação com sistema deordenhamanual emecânica. O leitecoletado foi submetidoa testesfísicoquímicos, microbiológicos e à contagem de células somáticas (CCS). Os resultados foram comparados aos padrões estabelecidos pela Instrução Normativa no 51 . Das 301 amostras anal isadas, verificou-se que as médias para CCS variaram de $<400.000$ a 1.000 .000 células/ mL, a acidez (Do) de 19,03 a 19,40, a gordura (\%) de 3,34 a 3,56, o EST(\%) de 12,04 a 11,89 , ESD (\%) 8,53 a 8,17, a lactose (\%) de 4,43a 4,48; proteína (\%) de 3,06 a 3,12 econtagem bacteriana total de 1,8x $10^{9}$ a 4,0 x $10^{9} \mathrm{~mL}$. A maioria das amostras encontravam-se dentro dos padrões exigidos pela instrução normativa no 51, contudo há necessidade de revisão dos procedimento na produção leiteira e introdução de um programa de educação sanitária na região.

PALAVRAS-CHAVE: Contagem de células somáticas, leite, vaca.

\section{ABSTRACT}

SOMATIC CELL COUNT (SCC) AND PHYSICOCHEMICAL AND MICROBIOLOGICAL PATTERNSOF TYPE C MILK FROM THE A GRESTEREGION, OF PERNAMBUCOSTATE,BRAZIL. Thisstudy was desi gned to eval uatetheeffects of somatic cell count (SCC) on milk quality from 13 dairy farmsaccordingtofederal regulations of M inistério daA gricultura, PecuáriaeA bastecimento (A gricultureM inistry of Brazil). Threehundred and onesamples of typeC milk werecollected by hand and by milking machine. Thesamples weretested for physicochemical, cytological (SCC) and aspects. Theresults showed SCC ranging from 400,000 to 1,000,000 cells/ mL; acidity varied from of 19.03 to $19.40 \mathrm{O}$; total fat (3.34\% to $3.56 \%)$; total solids ( $12.04 \%$ to $11.89 \%)$; solids not fat $(8.53 \%$ to $8.17 \%$ ); lactose (4.43\% to a $4.48 \%$ ); protein (3.06\% to $3.12 \%)$ and the bacterial count ( $1.8 \times 10^{9}$ to $\left.4.0 \times 10^{9} \mathrm{~mL}\right)$. According to federal regulations no differences in physicochemical and cytological (SCC) patterns of milk werefound in thesesamples, but a continuous education program must be installed in thisarea to providemilk quality.

KEY WORDS: Somatics cells count, milk, cow.

\section{INTRODUÇÃO}

É cadavez mais visível a preocupação dosórgãos de saúde com relação a qualidade dos alimentos disponíveis para o consumo. No Brasil, com relação à qualidadedo leite, vários temas têm sido debatidos com foco principal na qualidade da matéria-prima, controledo processo emanutenção dasua qual idade.
Entreesses, destaca-seo pagamento do leitebaseado emcritérios dequalidadedamatéria-primafornecida aoslaticínios. Observa-seaimportância desseassunto, uma vez que culmina com a bonificação dos produtores rurais visando garantir o fornecimento de matéria-prima de boa qualidade.

Assim, a busca pela qual idade exigirá da atividade leiteira do Brasil várias modificações. Em 18 de

${ }^{2}$ M édico Veterinário Autônomo, Recife, PE, Brasil. 
setembro de2002, o Ministério da Agricultura, Pecuária eA bastecimento (MAPA), por intermédio do Departamento del nspeção deProdutos deOrigem A nimal (DIPOA) publicou ainstruçãonormativano51no Diário Oficial da União. Esta normatiza a produção e estabelece critérios e parâmetros de identidade e qualidadedoleite, desdeaordenha, oresfriamentona propriedaderural eseu transporteagranel, incluindo requisitos físico-químicos e microbiológicos, contagem de células somáticas (CCS) elimites máximos de resíduos (LMR) de antimicrobianos. Baseado nessa novalegislação eatendidosos critérios preconizados por ela, acredita-se quea médio elongo prazo, o leite terá melhor qualidade, os produtores, melhor remuneração eo país disporá de um produto que venha a atender os padrões internacionais, ampliando e possibilitando as exportações no setor.

Partindo desse princípio, o diagnóstico da atual situação da qualidade do leitecru produzido, tornasenecessário, visto quetal Instrução N ormativadetermina prazos paraqueoleiteproduzidoem diferentes regiões atenda aos padrões estabelecidos PICININ, 2003). Os produtores das regiões N orte/ Nordeste terãoaté2010paraproduziremleitecomCCSmáxima de 1.000 .000 de céls./ $\mathrm{mL}$, quando diminuem para 750.000 células/ mL e a partir de 2011, o parâmetro será de 400.000 céls./ mL para todas as regiões do país. Para queos produtores forneçam leitecru coma qual idadeexigidaeasindústrias laticinistas estejam preparadasparatodaamudança, éprecisomonitorar a real qualidade da matéria-prima segundo os critérioseparâmetros propostospela novalegislação. Isto éimportante, poisdarásuporteparaaimplementação demedidascorretivasvisando amel horiadaqualidade do leite (BrasiL, 2002).

Segundo dados da International Dairy Federation (1987), o teor de sólidos no leite apresenta uma alta correlação comorendimento industrial paraaprodução dederivadoslácteos, como o queijo eo leiteem pó, devendo assim, ser val orizados pela indústria.

Os critérios utilizados para garantir a qualidade higiênica doleitesão variadoseadotadosem praticamentetodos os países queapresentamumaindústria láctea desenvolvida. Os parâmetros, voltados paraa qualidade microbiológica do leite, são usados como critériodeaceitação por partedaindústriaedentroda legislação oficial de cada país ou região. Contudo, fora a regulamentação oficial, algumas indústrias utilizam tais critérios para bonificação do leite (FonSECA, 2001).

Os parâmetros relacionados com a qualidade higiênica são muitos e incluem desde a contagem bacteriana total (CBT) ou contagem global (CG) atéa contagem de células somáticas (CCS) (PICININ, 2003).

Segundo Crquera et al. (1999b), a melhor forma de retardar a perda de qualidade, mantendo estáveis as característicasdoprodutoéobtidaatravésdoresfriamento eainda, das condições detransportea granel.

De acordo com a nova legislação brasileira, 1,0x $10^{6} \mathrm{UFC} / \mathrm{mL}$ é o número máximo de Contagem Bacteriana Total (CBT) até 2008, para as regiões Sul, Sudeste e Centro-Oeste; e, até 2010 para as regiões N orteeN ordeste. Destaforma, as contagens serão de no máximo 7,5 x $10^{5} \mathrm{UFC} / \mathrm{mL}$ de CBT, sendo ainda considerada a partir de 2011, o máximo de 1,0 × $10^{5}$ $\mathrm{UFC} / \mathrm{mL}$ no caso de tanques individuais e $3,0 \times 10^{5}$ UFC/ mL paraleitedeconjunto, paratodasasregiões (PICININ, 2003). Ficafacultadoaosestabelecimentosde laticíni os anteci parem-se aos prazos fixados na Instrução N ormativaN ${ }^{\circ} 51$ doM inistério daA gricultura, Pecuária e A bastecimento (BRASL, 2002).

A adequadahigienedaglândulamamáriaétalvez a medida isolada mais importante na prevenção de novas infecções intramamárias. Existe uma relação direta entreo número debactérias presentesnos tetos e a taxa de infecções intramamárias. Desta forma, todosos procedimentosquecontribuam paraamanutenção deuma baixa população debactériasnasuperfície dos tetos ajudam de forma significativa no controle da mastite (FonseCA \& SANTOS, 2000).

Ficou estabelecidoquea partir 2005, a CCSmáxima permitida no leite cru refrigerado será de $\mathbf{1 . 0 0 0 . 0 0 0}$ células/ mL para as regiões Sul, Sudeste e Centro Oeste. Tal padrãolegal éválidoaté2010 paraas regiões Norte e Nordeste, quando diminuem para 7,5 X $10^{5}$ céls./ mL. A partir de 2011, para todas as regiões, 0 padrão passa a ser de 4,0 $\times 10^{5}$ céls./ mL (BraSL, 2002).

Considerando tais aspectos e ressaltando a importânciadaqualidadedoleiteea ausência detrabaIhos na literatura regional sobre o tema abordado, realizou-se este estudo a fim de oferecer subsídios paraa avaliação da qualidadedo leitecru produzido em propriedades rurais do Agreste do Estado de Pernambuco, avaliada pela contagem de células somáticas (CCS) do leite dos rebanhos bovinos leiteirosepelaqualidadefísico-químicaemicrobiológica.

\section{MATERIAL E MÉTODOS}

Foram anal isadas 301 amostras de leite de vacas puras ou mestiças em diferentes estágios delactação. O leite foi col etado de todos os animais que não se encontravam em período colostral e em fase de secagem, ou ainda aqueles em tratamento.

Para determinação da qualidade do leite, foram sel ecionadasao acaso, 13propriedades ruraislocalizadas no Agreste do Estado de Pernambuco, representadas por pequenos emédios produtores de leite, com ordenhas do tipo manual e mecânica.

As amostrasforam coletadas, assepticamente, como auxílio de conchas plásticas desinfetadas com álcool 
70\%e, posteriormente, secascomtoal hasdepapel. Oleite eracoletadoemfrascosestéreis, emduasalíquotas, sendo a primeira representada por 301 amostras representativasdasordenhasindividuaisrealizadasnaspropriedades. Estasforamacondicionadasemfrascosestéreiscontendobronopol, colocadasemcaixasisotérmicascontendo gel o etransportadas ao laboratório, ondeforam realizadasas seguintesanálises: determinação dosteores de proténa, lactose, gordura, extrato seco total, econtagem de células somáticas (CCS). A segunda alíquota correspondiaaum "pool" deamostras decada propriedadeeeratransportada, sob refrigeração, paraarealização de análises microbiológicas (contagem padrão em placaepesquisadecoliformes), alémdotestederedutase.

As análises físico-químicas referentes aos teores delactose, proteína, gorduraeextrato secototal foram realizadas utilizando-se equipamento el etrônico Fossomatic, com capacidadedeanálisede 300 amostras/ hora, cujo princípio analítico baseia-se na absorção de comprimento de onda na região infra-vermelha (National Mastitis Council, 1999).

As análises microbiológi cas foram realizadas de acordo com STANDARD (1992). Para o testederedutase, seguiu-se técnica descrita por Demeter (1969).

Para a contagem de células somáticas, utilizou-se equipamento eletrônico - Fossomatic, com capacidade de análise de 300 amostras/ hora, cujo princípio analítico baseia-se na citometria de fluxo (N ATIONAL MASTITIS CounCIL, 1999).

A pós efetuadasas análises do leitecru, os resultadosforam submetidosàanál iseestatística descritiva, além decomparação demédias pelotestet deStudent, considerando-seo nível deconfiança de $95 \%$, segundo SnedeCor \& Cochran (1989).

\section{RESULTADOSE DISCUSSÃO}

A maioria das amostras de leite analisadas apresentou de contagens de células somáticas do abaixo de 400.000 céls $/ \mathrm{mL}$, sendo considerado satisfatório, deacordo com os padrões preconizados pela instrução normativa n51 (BraSL, 2002).

Os valores das contagens de células somáticas variaramde8.000a8.291.000células/ mL, commédia de402.126 céls./ mL Considerando o padrão deCCS preconizado pela legislação brasileira (BRASL, 2002) para a região Nordeste, como máximo de 1.000 .000 células/ mL, demonstra-sequeas trezepropriedades rurais estudadas estavam produzindo leitecom CCS que atenderia ao padrão estabelecido, já que foram encontrados val ores médios inferiores a esse valor, apesar deterem sido registradas CCS deamostras de leite individual superiores a $1.000 .000 / \mathrm{mL}$.

A influência da concentração de células somáticas sobre os constituintes do leite é muito discutida. Alguns autores (KING, 1978, citado por MunRo et al .,1984; Roger et al., 1989a) afirmam que o aumento significativo de células somáticas (acima de 500.000 céls./ mL) leva a redução do teor de gordura. KING (1978) citado por MunRoetal. (1984), encontrou umaquedasignificativa do teor de gordura, comparando quartos não infectados com quartos com CCS superior a 500.000/ mL. Porém, Munro et al. (1984) não encontraram diferençassignificativasnoteor degorduradeamostras de leitequeapresentavam CCS entre 250.000 e 500.000/ $\mathrm{mL}$. Estudo realizado por PICININ (2003), em 31 propriedades leiteiras na Região Metropolitana deBelo Horizonte, demonstrou-sequequanto maioraCCS, menores os teores do gordura e EST do leite. No presente estudo, verificou-se que houve aumento no teor de gordura (Tabela 1) à medida que a CCS aumentava, diferindoassimdosresultadosencontradosporPICININ (2003). ObservandoaCCSemrelação ao EST, notou-se que este aumentou a medida que a concentração de células somáticas aumentava, considerando médias de até 750.000 células/ mL, diminuindo no intervalo entre751.000a 1.000.000decélulas/ mL, o queconcorda com os resultados obtidos por PICININ (2003).

ComrelaçãoaosteoresdeESD, proténaelactose, todos apresentaram médias el evadas, sendo aquelas referentes à ESD eà proteína superiores aos valores mínimos estabelecidos pela instrução normativa n51 (BRASL, 2002). Esses val ores são semel hantesàqueles encontrados por PICININ (2003). Alguns estudos mostram uma diminuição doteor delactoseemrelação ao aumento da contagemdecélulassomáticas ( Munroet al., 1984; Politis \& NG-Kwal-H ANG, 1988). Porém, no presente estudo, houvevariação dalactose, quando, por exemplo, oleite apresentava maior intervalo médio deCCS. Observouse, ainda, uma redução no teor de lactose quando o intervalo deCCS estava entre 401.00 e $750.000 / \mathrm{mL}$.

Tabela 1 - Médias dos diferentes parâmetros físico-químicos de leite produzido em propriedades do Agreste de Pernambuco e seus correspondentes interval os de CCS (céls./ mL).

\begin{tabular}{lcccccc}
\hline CCS (céls./ mL x 1000) & Acidez ( $\left.{ }^{\circ} \mathrm{D}\right)$ & Gordura (\%) & EST (\%) & ESD (\%) & Lactose (\%) & Proteína (\%) \\
\hline$<400$ & $19,03^{\mathrm{a}}$ & $3,34^{\mathrm{a}}$ & $12,04^{\mathrm{a}}$ & $8,54^{\mathrm{a}}$ & $4,44^{\mathrm{a}}$ & $3,08^{\mathrm{a}}$ \\
401 a 750 & $19,10^{\mathrm{a}}$ & $3,56^{\mathrm{a}}$ & $12,12^{\mathrm{a}}$ & $8,53^{\mathrm{a}}$ & $4,43^{\mathrm{a}}$ & $3,12^{\mathrm{a}}$ \\
751 a 1.000 & $19,40^{\mathrm{a}}$ & $3,36^{\mathrm{a}}$ & $11,89^{\mathrm{a}}$ & $8,17^{\mathrm{a}}$ & $4,48^{\mathrm{a}}$ & $3,06^{\mathrm{a}}$ \\
\hline
\end{tabular}

Médias seguidas por letras minúsculas na mesma coluna diferentes indicam diferença significativa $(p<0,05)$ 
A lactoseésintetizadapelo aparel ho deGolgi das células epiteliaissecretoras dosal véolosmamários. A mastite causa dano neste tecido e altera os sistemas enzimáticos nas células secretoras, tendo, como conseqüência, a diminuição da biossíntese desteconstituinte. Segundo KITCHEN (1981), níveis delactoseinferioresa 4,69 e 4,75\% podem ser indicativos demastite no rebanho. Valea pena sal ientar que a redução dos valores deparâmetrosfísico-químicos como caseína, lactose e gordura compromete diretamente o rendimento industrial, principal mente em relação a fabricação de queijos, chegando a uma queda de $5 \%$ na produção, além de prolongar o tempo decoagulação, firmeza do coágulo, expulsão do soro etaxadedesenvolvimento da acidez (Munro et al., 1984). Todosesses fatoresinterferem, diretamente, naqualidadedo produto final, diminuindo, assim, seu valor nutritivo, além deinterferir no val or pago por litro deleite, uma vez quevários destes parâmetros são utilizados para bonificar o produtor no sistema de pagamento por qualidade.

Segundo VERDI et al . (1987), não ocorrealteração no teor de proteína do leite e Le et al . (1991) afirmaram queo mesmoencontra-sediminuídoemleitedevacas com altas CCS. Por outro lado, KLel et al . (1998) rel ataramqueoleitedevacascomaltaCCSpodeapresentar maiores níveis de proteína total, secomparado como de vacas sadias. Em resumo, a concentração de proteínatotal noleitecomaltaCCSpermaneceinalterada ou sofre pequenas alterações.

A valiando a composição do leite de vários rebanhos por um período de 2 anos, VERDI et al. (1987), observaram que a relação caseína/ proteína total foi de 1 a $2 \%$ menor parao leitecomalta CCS. Tal redução na síntese de caseína no leite com al ta CCS pode ser explicada pela redução da capacidade de síntese e secreção decaseína em conseqüência do dano causado por toxinas bacterianas ao epitélio secretor. PAAPE et al. (1995), citaram que devido a ação das mesmas toxinas bacterianas, há o aumento na concentração de proteínas séricas no leitedurantea mastite, estando aumentadas, principalmente, as concentrações de albumina sérica e imunoglobulinas dos quartos infectados. Mesmo queexistam controvérsias sobreo efeito daCCS sobrea concentração da caseína, podeseafirmar queà medida quea CCS seeleva no leite, a relação caseína/ proteínatotal estádiminuída(Kelıet al., 1998).

No presente trabal ho observou-se que das propriedades estudadas, 53,84\% apresentaram média daCCSinferiores a 400.000 céls./ mL e30,76\% apresentaram contagens entre 401.000 a 750.000 céls/ $\mathrm{mL}$. No total de propriedades estudadas, $84,6 \%$ já apresentariamleitecom CCSdentro dolimiteestabelecido pela instrução normativa ${ }^{\circ} 51$ (BraSIL, 2002). Este resultad os pode ser considerado bastante con- siderável e animador para os produtores da região. Mendonça et al. (2001) estudando a contagem de células somáticas de 75 propriedades leiteiras de Minas Gerais, encontraram $12 \%$ das propriedades comleiteapresentandovaloresmédiosdeCCSsuperiores a $1.000 .000 / \mathrm{mL}$.

Nopresenteestudo, nãofoi observadovalor médio deCCSsuperior a 1.000.000/ mL, sendo queem $48 \%$ das propriedades, os valores médios variaram entre 400.000 a 750.000 céls/ mL. MACHADO (2000), ao estudar 37 rebanhos do Estado deSão Paulo, relatou CCS média de $833.000 / \mathrm{mL}$. Comparando os resultados deste autor ao encontrado no presente trabal ho, que foi de 402.126 células/ $\mathrm{mL}$, observa-se que a CCS média nas propriedades estudadas em Pernambuco foi inferior. Considerando-seo limitelegal para recebimento do leite na União Européia (400.000 céls./ $\mathrm{mL}$ ) e Canadá (500.000 céls./ mL), observa-se que a média que mais se aproxima desse valor é aquela encontrada nas propriedades estudadas em Pernambuco.

Das 301 amostras anal isadas, $71 \%$ apresentaram CCS menor que $400.000 / \mathrm{mL} ; 14,95 \%$ entre 401.000 a $750.000 / \mathrm{mL} ; 5,67 \%$ entre 7510000 a $1.000 .000 / \mathrm{mL}$ e $7,97 \%$, superior a 1.000 .000 céls./ $\mathrm{mL}$. No total de amostras, $86,38 \%$ atenderiam aos padrões máximos permitidos paraa Região Nordesteatéo ano de2010. Dentreas amostras que apresentaram CCSinferior a $400.000 / \mathrm{mL}, 41,86 \%$ tinham valores inferiores a $100.000 / \mathrm{mL}$. CCS inferior a $100.000 / \mathrm{mL}$ denota ausência do processo inflamatório da glândula mamária.

Julga-semeio temeroso afirmar isto, emboraéquase certo que sejaisto mesmo queaconteça, mas, na natureza, nem sempretudo éassim certinho. Então talvez fique melhor "sugere" que denota. Segundo SCHPPERS et al .(1997), quando o número decélulas somáticas no leite encontra-se entre 200.000 a $500.000 / \mathrm{mL}$ é recomendável o exame microbiológico para elucidar a situação. Por sua vez, quando severifica um número superior a 100.000 céls./ mL considera-sea presença de processo inflamatório na glândula mamária, sem no entanto, definir seo processo éinfeccioso ou otipo de processo inflamatório (agudo ou crônico).

A nalisando-seosresultados dequalidadedeleite e, considerando-se o tipo de ordenha utilizado nas propriedades, constatam-se variações quanto aos diferentesparâmetros(Tabela2). A contagemdecélulassomáticas, por exemplo, foi mais el evada $(p<0,05)$ no leitedepropriedades queutilizam ordenha mecânica, sugerindo aocorrênciadefal has nahigienização e, até mesmo, falta de manutenção do equipamento. Sabe-se que o equipamento de ordenha quando mal utilizado eem condições insati sfatórias pode contribuir para a veiculação de mi crorganismos causadores da mastite (CerQueira et al., 1999a). 
Tabela 2- Resultados médios deanálises físico-químicas, microbiológcaseCSSdeleitecru produzido emal gumas propriedades rurais do Agreste dePernambuco, deacordo com o tipo deordenha utilizada.

\begin{tabular}{|c|c|c|}
\hline \multirow[t]{2}{*}{ Análises } & \multicolumn{2}{|c|}{ Tipo de ordenha } \\
\hline & Manual & Mecânica* \\
\hline CCS (céls./ mL)**k & $373.000^{\circ}$ & $530.000^{a}$ \\
\hline $\begin{array}{l}\text { Enumeração de } \\
\text { coliformes (NMP/ mL) }\end{array}$ & $3,1 \times 10^{6 a}$ & $3,3 \times 10^{5 b}$ \\
\hline CBT (UFC/ mL)**k & $3,2 \times 10^{8 a}$ & $1,6 \times 10^{7 b}$ \\
\hline TRAM (minutos)**t*k & $180^{\mathrm{b}}$ & $354^{a}$ \\
\hline Acidez (oD) & $19^{a}$ & $19^{\mathrm{a}}$ \\
\hline Proteína (\%) & $3,10^{a}$ & $3,04^{a}$ \\
\hline Gordura (\%) & $3,54^{a}$ & $3,21^{a}$ \\
\hline Lactose (\%) & $4,47^{a}$ & $4,33^{a}$ \\
\hline $\mathrm{ESD}(\%)^{* 11 k 1 k}$ & $8,29^{a}$ & $8,29^{a}$ \\
\hline EST(\%)*1k1k1k & $12,14^{\mathrm{a}}$ & $11,53^{a}$ \\
\hline
\end{tabular}

*Ordenha mecanizada tipo balde ao pé.

**CCS = Contagem de células somáticas.

${ }^{*} *$ CBT $=$ Contagem bateriana total.

****TRAM =Tempo de reação do azul de metileno.

****ESD = Extrato seco desengordurado.

**k+kikEST $=$ Estrato seco total.

Médias seguidas por letras minúsculas na mesma linha diferentesindicamdiferençasignificativa $(p<0,05)$.

Tabela 3-Distribuição percentual dealgumas propriedades rurais do Agreste de Pernambuco quanto ao teste de redutase e sua relação com a Contagem bacteriana total média (CBT) doleite.

\begin{tabular}{lcc}
\hline TRAM* & Propriedades (\%) & ${ }^{* * C B T(U F C / ~ m L)}$ \\
\hline$<3$ horas & 38,5 & $2,2 \times 10^{9 a}$ \\
3 a 5 horas & 30,8 & $1,8 \times 10^{8 b}$ \\
$>$ 5 horas & 30,8 & $2,3 \times 10^{9 a}$ \\
\hline
\end{tabular}

*TRAM = Teste de Redutase utilizando o corante azul de metileno.

**CBT = Contagem bacteriana total.

Médias seguidas por letras minúsculas na mesma coluna diferentesindicam diferençasignificativa $(p<0,05)$.

Tabela 4 - Comparação entre médias de análises microbiológicas deleitecru produzido em algumas propriedades do Agreste de Pernambuco e seus correspondentesintervalos deCCS (céls/ mL).

\begin{tabular}{lccc}
\hline $\begin{array}{l}\text { CCS } \\
\text { (cél./ mL × 1000) }\end{array}$ & $\begin{array}{c}\text { TRAM } \\
\text { (Min) }\end{array}$ & $\begin{array}{c}\text { CBT } \\
(\text { UFC/ mL) }\end{array}$ & $\begin{array}{c}\text { NMP } \\
(\text { UFC/ mL) }\end{array}$ \\
\hline$<400$ & $237^{a}$ & $1,8 \times 10^{9 a}$ & $3,7 \times 10^{6 b}$ \\
401 a 750 & $153^{b}$ & $1,8 \times 10^{9 a}$ & $3,2 \times 10^{6 b}$ \\
751 a 1.000 & $218^{a}$ & $4,0 \times 10^{9 a}$ & $4,7 \times 10^{6 b}$ \\
\hline
\end{tabular}

Médias seguidas por letras minúsculas na mesma coluna diferentesindicam diferençasignificativa $(p<0,05)$
As contagens bacterianas, por outro lado, foram mais elevadas $(p<0,05)$ - como são log diferentes, mesmo semter acessoaos dadosindividuais, acredito quedevater sido diferençaestatisticamentesignificativa- no leite obtido manualmente, indicando fal has higiênicas no manejo deordenha. Isto aindapodeser confirmado pelo teste de redutase, que apresenta menor tempo deredução docorante $(p<0,05)$, quando comparadoao tempodereduçãonoleiteobtido mecanicamente. $O$ manejo adequado éum fator degrande importância na determinação da qualidade do produto. Picinin (2003), afirmou que um melhor manejo tem como conseqüência um leite com menores CCSe contagem bacteriana. Observou-se, ainda, quea CCS foi, em sua maior parte, inferior às contagens de microrganismos mesófilos e psicrotróficos, o que foi também constatado no presente trabal ho, em relação a contagem bacteriana total e número mais provável decoliformes. Isto caracteriza fal has no manejo, adici onais àquelas rel acionadas ao controle da mastite. Não houvevariação em relação aos parâmetrosfísicoquímicosobservadosnaTabela2, quando secompara o modo de obtenção do leite $(p>0,05)$.

Entre as treze propriedades rurais estudadas, 9 (69\%) produziamaté246 L deleite/ dia, sendo considerados pequenos produtores, e 4 (31\%) produziam entre 246 e 697,4L deleite/ dia (médios produtores). Os pequenos produtores destinavam o leite para fabricação de queijo coal ho e/ ou manteiga no local de produção, enquanto que os médios enviam todo o volumeproduzido paraoslaticínios. Quando secomparou o volume deleite produzido com a CCS, observou-sequeexisteuma variação grandeentreas médias dessesvalores, constatando-se, inclusive, quenem sempre nas propriedades que produzem o menor volume, há uma menor CCS no leite. PICININ (2003), comparando médias deprodução com CCS, concluiu que havia uma menor variabilidade na contagem do leite nas grandes propriedades. Isso sugerequenem sempre nas propriedades que produzem o maior volume de leitea CCSémaior.

A penas duas $(15,4 \%)$ propriedades estudadas tinham como rotina a prática da desinfecção dos tetos antes eapósa ordenha, o quelevariaa diminuição da CCS no leite. Segundo PHILPOT \& NiCKERSON (2002), a desinfecção dostetos anteseapósa ordenhareduz as novas taxas de mastiteem $50 \%$ no primeiro ano eem $75 \%$, no segundo ano. Assim, seria muito importante a adoção desta prática pelos demais produtores, visandoaobtenção deleitedemel hor qualidade. Segundo FonsECA et al . (2000), a implantação de um correto manejo de ordenha é de extrema importância para o controleda mastite, independentementedo tamanho do rebanho ou tipo de equipamento de ordenha. Ainda, segundo o mesmo autor, acorretadesinfecção dos tetos, associada a outras práticas (como limpeza 
das teteiras), são fatores relacionadoscom o maior ou menor risco de contaminação do leite.

A instruçãonormativanํ51do Ministério daA gricultura, Pecuária eA bastecimento (BraSL, 2002) preconizaumtempo mínimo de90minutosparaoTRAM para o leite cru tipo $C$. O resultado deste trabalho demonstra que o maior percentual de amostras analisadas apresentava tempos deredução abai xo desse padrão (Tabela 3), justificando, assim, a al ta contagem demicrorganismos detectada, atingindo valores acima do padrão oficial. Tal fato indica qualidade insatisfatória da matéria-prima. Isto podeestar associado, na maioria das vezes, a manejo inadequado de ordenhaefal hasnamanipulação dol eiteeutensílios que entram em contato com o leite, entre outros. De acordo com Cerqueira et al. (1994), no Brasil, em geral, o leiteé obtido em más condições higiênico-sanitárias, apresentando altas contagens de microrganismos, constituindo-se em risco à saúde pública, principalmente, quando consumido cru.

A contagem bacteriana total nos diferentes intervalos de CCS, não variou ( $p>0,05)$, como pode ser observado na Tabela 4, assim como para o número mais provável de coliformes $(p>0,05)$. Sabe-se que nãohá, necessariamente, umarel ação entrea el evada CCS e a CBT no leite. Contudo, a alta contagem bacteriana, mesmo com CCS abaixo de $400.000 / \mathrm{mL}$, implica em fal has higiêni cas no manejo deordenha. Segundo YAZID \& MoHD YAZID (1990), contagens microbiológicas el evadas significam perda de qualidade do produto. Mesmo tendo sido consideradas semel hantes CBT e NMP decoliformes entre os diferentes grupos deCCS(Tabela 4), o tempo de redução do azul de metileno foi menor para o estrato que variavade401a 750células/ mL. Talvez, isto podeser explicadoporquenemtodososmicrorganismosapresentam produção igual de enzimas oxiredutoras no leite (JAY, 1996).

\section{CONCLUSÃO}

Amostras deleite cru tipo $C$, produzido na região A greste do Estado de Pernambuco, em sua maioria, apresentaram CCS e valores dos parâmetros físicoquímicos dentro dos padrões exigidospelainstrução normativa $\mathrm{n}$ - 51 do Ministério da A gricultura, Pecuária e A bastecimento. Por outro lado, os resultados dasanálisesmicrobiológicassugeremaocorrênciade fal has no manejo higiêni co-sanitário na obtenção do leite.

Há necessidade de rever os procedimentos de ordenha e higienização de equipamentos, assim como autilização detanques refrigerados, queassociado ao manejo correto, possam proporcionar uma melhoria da qual idade de leite. Dessa forma, sefaz necessário a introdução de um programa de educação sanitária, junto aos produtores ebeneficiadores doleiteparamel horar aqualidadedo produto eseus derivados.

REFERÊNCIAS

Brasil. Ministério da Agricultura, Pecuária e A bastecimento. Instrução normativa $\mathrm{N}$-51 de 18 desetembro de 2002. Regulamento Técnico de Produção, IdentidadeeQualidadedo LeiteTipoA, do LeiteTipoB, do Leite Tipo C, do Leite Pasteurizado e do Leite Cru Refrigerado eo Regulamento Técnico da Coleta de Leite Cru Refrigerado e seu Transporte a Granel. D iário 0 ficial da U nião, Brasília, DF, 18 deset. de2002. Secção 3. Disponível em: <http:/ / www .agricultura. gov.br/ das/ dipoa/ in51.htm >. A cesso em: 25 set. 2002.

Cerqueira,M.M.O.P.;Souza, M.R.; Fonseca, L.M.;Rodrigues, R.; RUBINICH , J.Surto epidêmico detoxinfecçãoalimentar envolvendo queijo tipo Minas Frescal em Pará de Minas. Arquivo Brasileiro de $M$ edicina Veterinária e Zootecnia, v.46, n.6, p.723-728, 1994.

Cerqueira, M.M.O.P.; Sena, M.J. de; Souza, M.R. de; Leite, M.O.;PEnNA, C.F. de A.M. A valiação da qualidadedo leite estocado em tanque deimersão eexpansão por 48horas. Revista do Instituto deL aticínios CândidoT ostes, v.54, n.309, p.251-254, 1999a.

Cerqueira, M.M.O.P.; Souza, M.R. de; Sena, M.J. de; Leite, M.O.; Penna, C.F. DE A.M. Fatores determinantes na qualidadedo leite: estudo deumaindústria delaticínios. Revista do Instituto de Laticínios Cândido Tostes, v.54, n.309, p.241-245, 1999b.

Demeter, K.J. Lactobacteriologia. Zaragoza: Acribia, 1969. $79 p$.

FonseCA, L.F.L. \& SANTOS, M.V.Q ualidadedo leiteecontrolede mastite. São Paulo: Lemos Editorial, 2000. 175p.

Fon SECA, L.F.L. Pagamento por qual idade: situação atual e perspectivas para o setor lácteo brasileiro - parte 01. Disponível em: <http:/ / www.milkpoint.com.br/ $\mathrm{mn} /$ utils/ print.asp?id artigo $=1209>$. A cesso em: 5 set. 2001

International Dairy Federation - IDF. Bovine mastitis: definition and guidelines for diagnosis. Bulletin of International D airy Federation, Brussels, v.211, p.1-24, 1987.

JAY, J.M. M odern Food M icrobiology. N ew York:International Thompson Publishing, 1996. 661p.

Kitchen, B.J. Review of the progress of dairy science: bovine masstitis: milk compositional changes and related diagnostic tests. J ournal of D airy R esearch, v.48, n.1, p.167-188, 1981.

Klei, L.; Yun, J.; Sapru, A.; Lynch, J.; Barbano, D.; Sears, P.; GALTON ,D. Effects of milk somaticcell counton Cottage cheese yield and quality. Journal of Dairy Science, Champaign, v.81, n.5, p.1205-1213, 1998.

Lee, S.C.; Yu, J.H.; Jeong, C.L.; Back, Y.J.; Yoon, Y.C. The influence of mastitis on the quality of raw milk and cheese. Korean J ournal of D airy Science, v.13, n.1, p.217223, 1991. 
Machado, P.F. \& Pereira, A.R. Programa de análise de rebanhos leiteiros e da qual idade do leite- ESALQ/ USP.In: SIMPÓSIO INTERN A CIONAL SOBRE QUALIDADE DO LEITE, 1., 1998, Curitiba.A nais. Curitiba: UFPR, 1998. p.85-88.

Machado, P.F. Contagem de células somáticas e seus efeitos sobrea qualidade do leite. Revista Indústria de Laticínios, v.5, n.29, p.54-56, 2000.

Mendonça, A.H.de;Penna, C.F.deA.M.;C erquelra, M.M.O.P.; Souza, M.R. de; Siqueira, T.M.L.; Camargos, C.R.M. Qualidadefísico-química deleitecru resfriado:comparação dediferentes procedimentoselocaisdecoleta. Revista do Instituto Laticínios Cândido Tostes, v.56, n.321, p.276-282, 2001.

Munro,G.L.;G rieve, P.A.; KitCHen, B.J. Effectsofmastitison milk yield, milk composition, processing properties and yield and quality of milk products. TheA ustralian Journal of D airy Technology, v.39, n.1, p.7-16, 1984.

National Mastitis Council (NMC). Laboratory nandbook on bovine mastitis. Madison: NMC, 1999. 222p.

PAAPE, M.J. Theleukocyteas a defensemechanism.J ournal of the A merican M edical A ssociaton , v.170, n.10, p.1214 1223, 1977.

PAAPE, M.J.;C apuco, A.V.; Guidry, A.J. Morphology, function and adaptation of mammary cells in normal and disease states. Journal of A nimal Science, Champaign, v.73, p.1-17, 1995. Supplement 2

PhilPot, W.N. \& NiCKerson, S.C. V encendo a luta contra a mastite. São Paulo: Milkbizz, 2002. 192p.

PICının, L.C. A Qualidade do leite e da água de algumas propriedades leiteiras de M inas Gerais: 2003. 89f. Dissertção (Mestrado) - Universidade de Minas Ge rais, Belo Horizonte, 2003.
Politis, I. \& NG-Kwal-Hang, K.F. Effects of somatic cell count and milk composition on cheese composition and cheesemaking efficiency.J ournal of D airy Science, v.71, n.7, p.1711-1719, 1988.

Rogers, S.A.; MItCHelL, G.E.; BARTLEY, J.P. The relationship between somatic cell count, composition and manufacturing properties of bulk milk. 4. N on-protein constituents. A ustralian Journal of Dairy Technology, v.44, n.2 p.53-56, 1989.

SCHALM, O.W. Pathologicchangesin themilk and udder of cows with mastitis. Journal of the A merican M edical A ssociation, v.170, n.10, p.1137-1140, 1977.

Sinedcor, G.W. \& Cochran, W.G. Statistical methods. 8.ed. A mes: Iowa StateUniversity, 1989. 503p.

STANDARD methods for the examination of dairy products: american public health association. 16.ed. Washington, DC: Robert T. Marshall, 1992. 546p.

TRonco, V.M. M anual parainspeçãodaqualidadedoleite. Santa Maria: Universidade Federal de Santa Maria, 1997. $166 \mathrm{p}$.

Verdi, R.J.; Barbano, D.M.; Dellavalle, M.E.; Senyk, G.F. Variabilityintrueprotein, casein, nonproteinnitrogen, and proteolysis in high and low somatic cell milks. J ournal of Dairy Science, v.70, n.2, p.230-242, 1987.

YAzID, B.H.A.M.M. \& Mord Yazid, B.H.A.M. Effects of low temperaturestorageand thermisation on thequality of raw and heat treated milk. Universitiesbof GreatBritain and Ireland and the Council for National Academic Awards, 1990. p.1585. (Index to Theses).

Recebido em 16/ 12/ 05

Aceito em 17/ 2/ 06 